\title{
IDEAH
}

\section{Managing Digital}

Scholarship Projects at

Many Levels: The

Immersive Scholar Cohort,

Residencies, and the Shift

to "Project Development"

Shelby Hallman ${ }^{1}$, Erica Y. Hayes ${ }^{2}$, Walt Gurley ${ }^{3}$, Micah Vandegrift ${ }^{3}$

${ }^{1}$ Loyola Marymount U, ${ }^{2}$ Villanova U, ${ }^{3}$ North Carolina State U

Published on: Jan 03, 2022

License: Creative Commons Attribution 4.0 International License (CC-BY 4.0). 
In 2017, the North Carolina (NC) State University Libraries was awarded a grant from the Andrew W. Mellon Foundation to develop extensible models and programs for the creation and impact of digital scholarship in large-scale and immersive visualization environments. The grant had two primary goals: first, to form a community of practice of scholars, technologists, and librarians who are working on developing large-scale visualization projects, and second, to address the lack of technical standards and guidelines for interoperability, sharing, evaluating, and reproducing digital scholarship in immersive visualization environments. For definitional purposes throughout this piece, immersive visualization is a general term used to describe environments such as large-scale visual display spaces or virtual reality head mounted displays that provide a user with an immersive multimedia experience.

To meet these goals, Immersive Scholar (the grant's working title) consisted of three specific elements: a series of five sub-grants for partnering institutions to develop new technologies, best practices, or projects that limited the barriers to participating in these large-scale visualization environments; a creative residency program hosted at the Libraries to create new, scalable digital scholarship works to be shared at peer institutions and displayed on the visualization walls in the James B. Hunt Jr. Library at NC State; and a culminating symposium to assess the results of the grant and transition into a new phase of scholarly communication production and evaluation of large-scale immersive visualizations (Vandegrift et al.).

With many individuals involved and multifaceted goals to address, the Libraries were tasked with the management of multiple projects, workflows, and product outcomes all within the larger framework of the grant's goals. Over the course of three years, the Immersive Scholar team developed guidelines, workflows, and a documentation model that captures the processes, contributors, timeline, scope, and outcomes of this multilayered grant. This piece presents the opportunities and challenges the project team faced while managing the grant and discusses the overall structural challenges of managing digital scholarship projects within immersive visualization environments, along with the importance of sharing infrastructure models in order to disseminate new forms of scholarship and foster communities of practice.

\section{Visualization at the NC State University Libraries and Partner Institutions}

The academic visualization community has dealt with many challenges managing immersive visualization environments for research, teaching, and learning. One 
significant challenge has been the lack of shared infrastructure for displaying visualization content across institutions. The James B. Hunt Jr. Library at NC State is unique in that it has six visualization walls which require individually crafted technologies, infrastructure, and technical expertise to maintain them. Similar to other institutions, developers at the Libraries created custom technology to support each of these visualization walls. For example, due to the scale and unique configuration of each visualization wall, the Libraries run and manage content utilizing an in-house

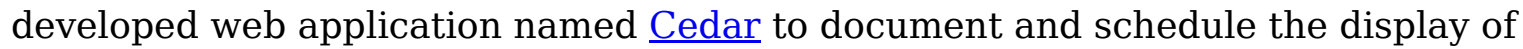
media on the visualization walls." While custom technology has allowed the academic visualization community the ability to share visualization content at their individual institutions, it has also limited the impact and utilization of the scholarship created within these visualization environments to be shared. To address these challenges, the Libraries awarded a series of subgrants to five institutions to develop a community of practice for sharing best practices and collaborative frameworks for visualizing digital scholarship in immersive visualization environments and to work toward lowering the barriers to sharing content across institutions. $\underline{1}$ These institutions included Brown University, Indiana University Bloomington (IU), University of Illinois at UrbanaChampaign (Illinois), Virginia Commonwealth University (VCU), and University of California, Berkeley (UC Berkeley).

Cohort projects ranged in scope from documentation and guidelines to immersive visual content and software applications and development frameworks. VCU developed a common framework to aid institutions when deciding how to implement large-scale visualization spaces. The outcome of this development was $\underline{A \text { Common Framework for }}$ Planning Visualization Environments, a thorough description of the important considerations for planning visualization spaces and services (Johnson). Two cohort projects produced tools to aid in the distribution of immersive visualization content:

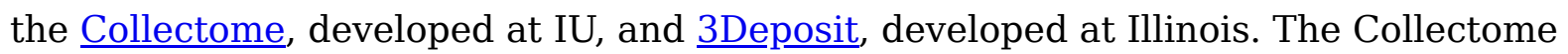
provides a web-based content-sharing platform to facilitate the curation, sharing, and display of content across large-format displays while 3Deposit is an installable storage, distribution, and management platform for 3D-content. In addition to 3Deposit, the Illinois cohort also developed Ginger, a suite of tools to generate and edit web-based VR tours from $360^{\circ}$ photos. The UC Berkeley team developed a collection of tools and workflows to aid photogrammetry techniques and produced a collection of 3D models using these techniques. Finally, Brown University developed $\underline{\text { Glider}}$, a web-based framework for creating interactive distributed applications for display on large-scale display walls. Glider provides a modular, extensible toolkit for users with a broad 
range of technical expertise, content, and applications. Each of these products serve in some capacity to support the creation, distribution, and display of immersive visualization content.

\section{Creative Residencies}

In addition to the individual cohort institutional projects, NC State University Libraries hosted six creative residencies between August 2018 and October 2020. These residencies focused on building scalable and open-source visualization works for the Libraries' visualization walls, with the goal of sharing them at peer institutions and increasing the impact of these works as scholarly outputs. These residencies are described below to provide context for the lessons learned and project development approach expounded upon in the following sections.

\section{Tess-Celestial}

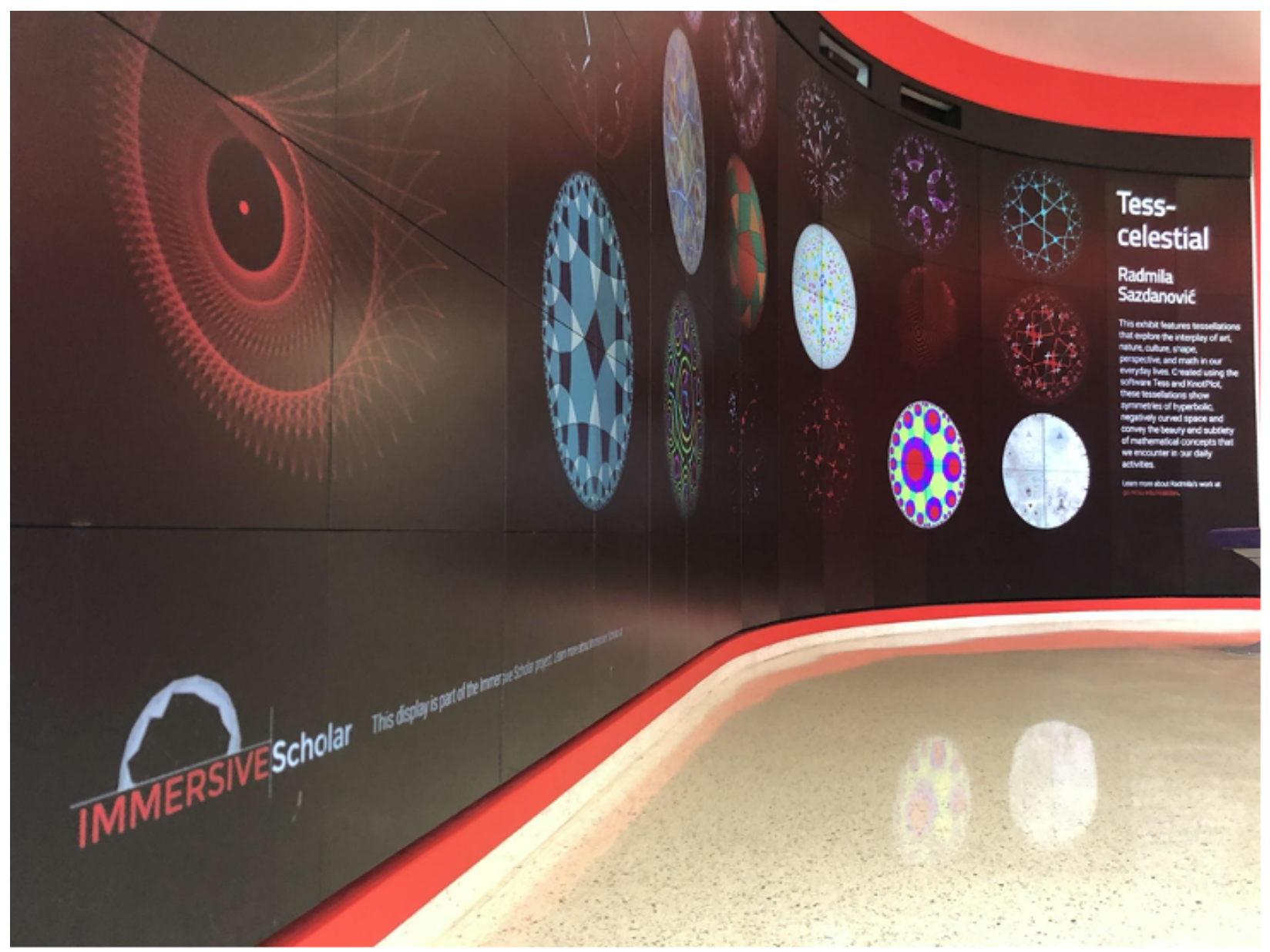

Figure 1: Radmila Sazdanović's Tess-Celestial, displayed at the NC State University Libraries, Raleigh, North Carolina, in 2018. Photo by Micah Vandegrift. 
In the summer of 2018--July 1 to August 18--Radmila Sazdanović, an assistant professor from the Department of Mathematics at NC State, joined the Libraries as the

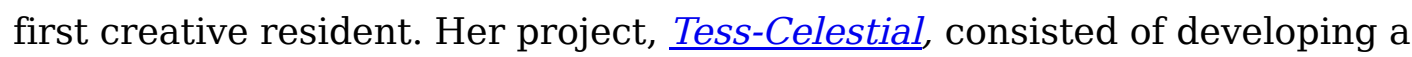
visualization featuring twenty-one tessellations (Figure 1). Using the software Tess and KnotPlot, Sazdanović's tessellations displayed symmetries of hyperbolic, negatively curved space, exploring the interplay of art, nature, culture, shape, perspective, and math in our everyday lives. With only six weeks to develop her project, the Immersive Scholar team met with Sazdanović early on to outline its goals. The team decided to divide the goals of her project across two functional teams, one focusing on creating the exhibit display of her visualization and the other on developing a grant proposal for extending Sazdanović's research and its impact. Both teams met twice weekly for the length of the creative residency, with concurrent check-in points across both teams as the project came to fruition. One major contribution to the project was from Jasmine Lang, an undergraduate student assistant from the College of Design at NC State, who specialized in UX design and helped conceptualize the project's display and front-end web development. To ensure the adaptability and shareability of the project, a web responsive framework hosted from GitHub pages was used in the display of Sazdanović's visualization (Gurley et al.).

\section{Coded Glass}

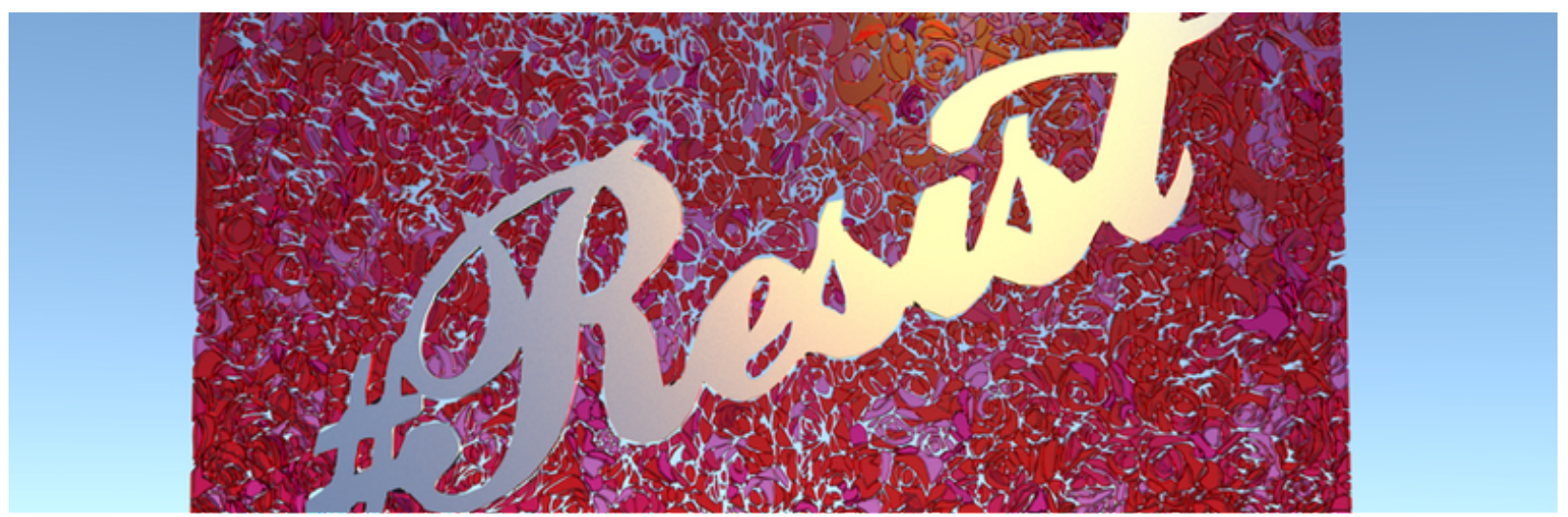

Figure 2: Liss LaFleur's Coded Glass, on display at the NC State University Libraries, Raleigh, North Carolina, in 2018.

Our second residency took place from August 16 to September 23, 2018, and hosted Liss LaFleur, an Assistant Professor of New Media in the Department of Studio Art at the University of North Texas. Exploring the urgency of the \#MeToo movement, her project Coded Glass consisted of a series of virtual stained-glass windows of protest signs, emojis, and hashtags from the \#MeToo movement and Boston's Art of the March Archive (Figure 2). Similar to the first residency, two simultaneous teams developed 
the project with LaFleur, one focused on text and data mining and the other on outreach and the design of the work itself. The data team collected, cleaned, and analyzed 2.5 million \#MeToo tweets posted between October 1, 2017, and August 15, 2018, as source material for the project. As this functional team worked toward data collection and text analysis, the other team focused on project scoping, outreach, and responsive front-end web development.

\section{Community Gardens}

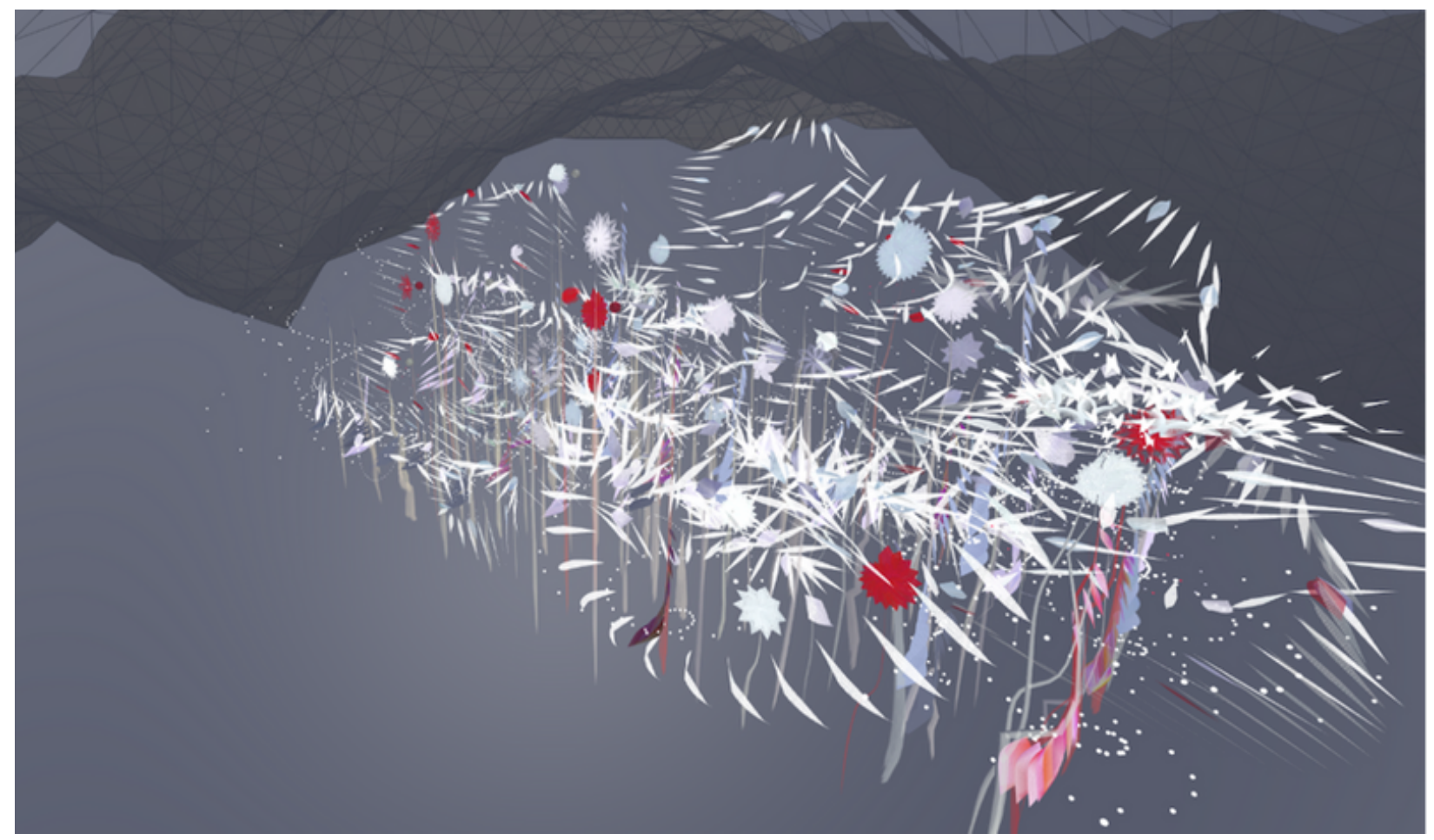

Figure 3: Lucas Swick's Community Gardens, on display at the NC State University Libraries, Raleigh, North Carolina, in 2018.

Lucas Swick, a generative artist from Portland, Oregon, joined the Libraries from October 1 to November 9,2018 . Unlike the previous two creative residents that came from academic institutions, Swick had a background in front-end engineering and experience creating generative art installations for organizations such as Capital One and MEZR. The source material for Swick's visualization work was a study by Mary Haskett from NC State's Department of Psychology on food and housing insecurity in the NC State student body (Haskett and Majumbder; Haskett et al). Using the collected data from the study, Swick developed Community Gardens, a generative art visualization that uses digital gardens as a visual metaphor for this difficult topic (Figure 3). During his creative residency, the Immersive Scholar team once again created two working teams to assist Swick with the development of his project. One of 
the teams focused on research and data collection, while the other focused on outreach, event planning, and marketing. The first team assisted Swick with researching native plants of North Carolina, so his virtual gardens would include plants from the local area. Each student was represented in Swick's visualization by a North Carolina plant featuring characteristics based on the student's data within Haskett's study. One challenge the Immersive Scholar team ran into while creating these metaphors for each student was determining how best to communicate the meaningful data behind Swick's visualization. To address this issue, the team worked with him to put together a website accompanying his visualization that includes detailed information about the various data points in Haskett's study and how they are represented in the gardens of Swick's visualization. In addition to putting together this website, the other team focused on marketing the project to increase its impact on campus. Two events during Swick's creative residency showcased his project, with one of the events collecting donations of canned foods for Feed the Pack, a campus-wide initiative to support NC State students suffering from food and housing insecurity and homelessness. 


\section{Surface Tension}

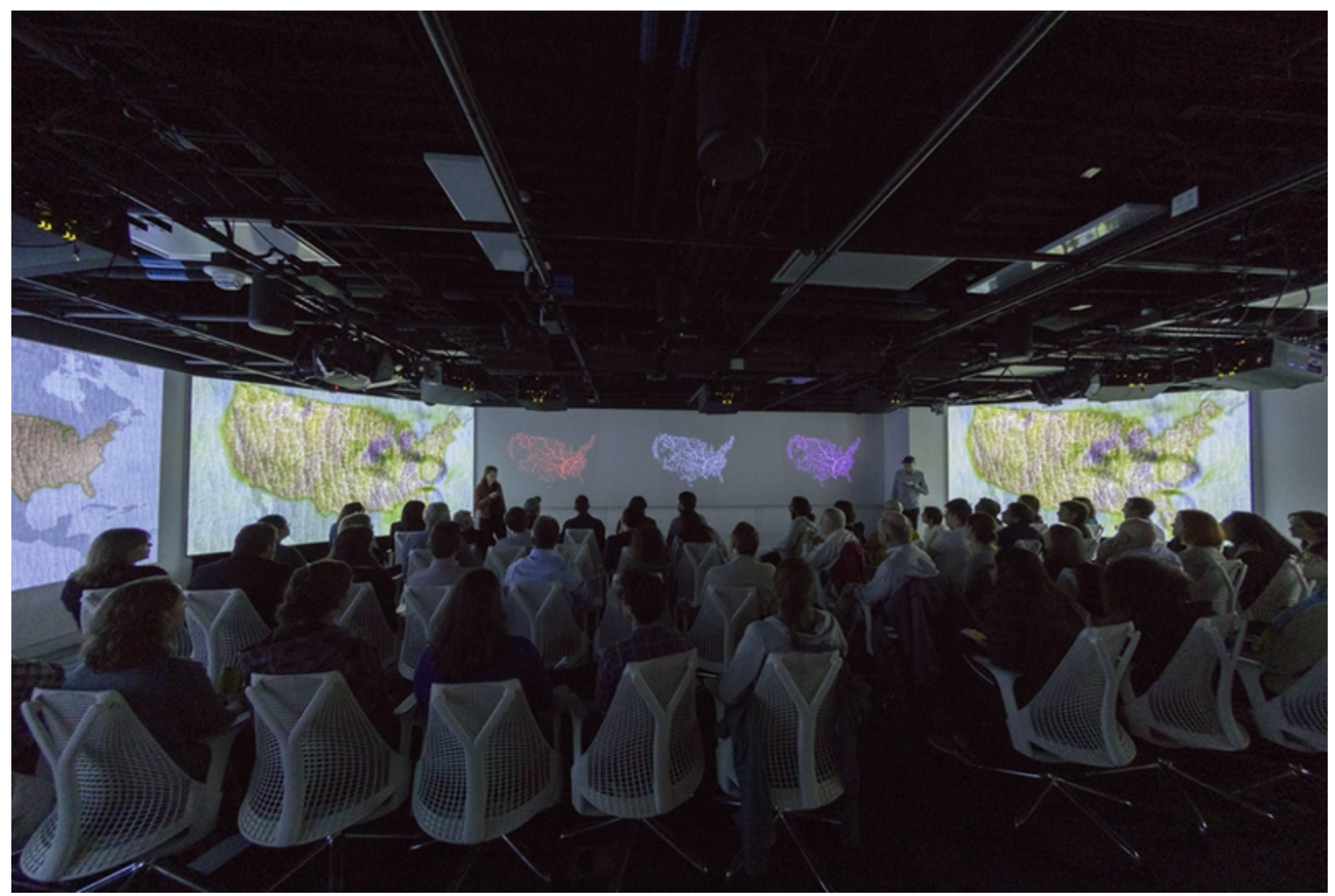

Figure 4: Caitlin and Misha's Surface Tension, displayed at the NC State University Libraries, Raleigh, North Carolina, in 2019. Photo by Brent Brafford (NC State University Libraries).

The first residency of 2019 welcomed the artist duo Caitlin and Misha (Caitlin Foley and Misha Rabinovich). Between February 25 and April 12, 2019, Caitlin and Misha

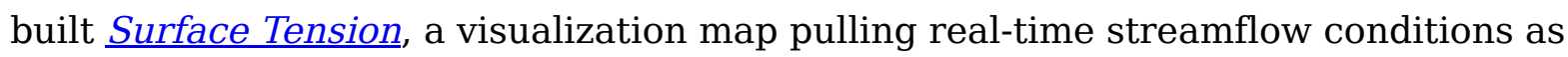
computed at United States Geological Survey (USGS) streamgages from the USGS WaterWatch Data Services (Figure 4). Focusing on humanity's fraught relationship with freshwater, Surface Tension represents the relative amount of water flowing through streams across the contiguous United States as water ripples emanating from USGS sampling locations on the date one is viewing the map. The data points on the map ripple out, influencing each other and combining into an aggregate pattern of interdependence. During the creative residency, the Immersive Scholar Team connected Caitlin and Misha with hydrologists at the USGS South Atlantic Water Science Center to inform the development of their project and the Water Resources Research Institute at NC State to organize the presentation of Surface Tension at a regional water science conference. 


\section{Untitled}

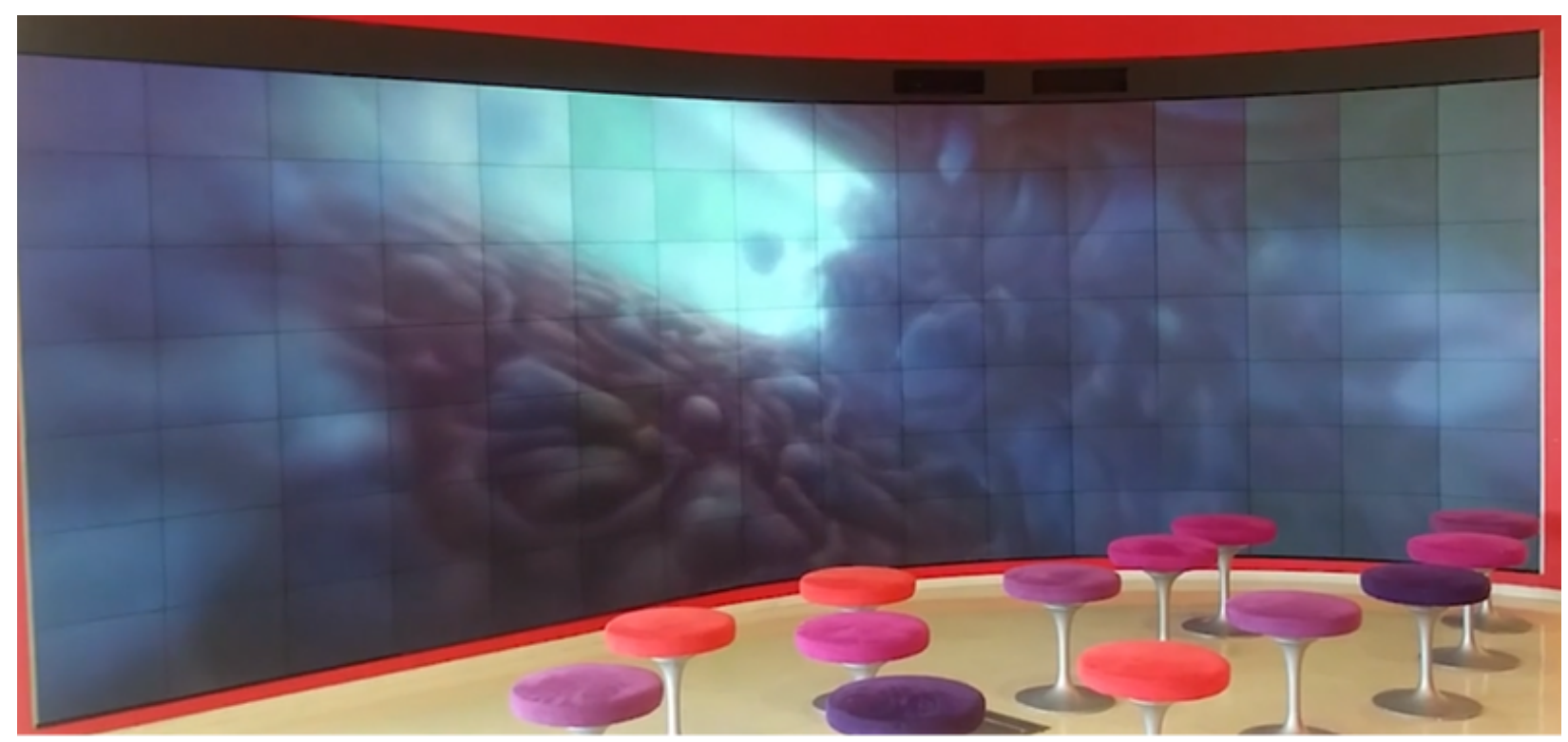

Figure 5: Emil Polyak's Untitled. Displayed at the NC State University Libraries, Raleigh, North Carolina, in 2019. A short video of Untitled is available online. Photo by Micah Vandegrift.

Over a four week period in the summer of 2019, Emil Polyak, a former NC State Assistant Professor of Art + Design, joined the Libraries for a residency focused on the development of an abstract visualization in which climate data indirectly contributes to the generation of real time animations that behave in surprising, calm, violent, organic, and mechanical ways at the same time to provoke emotions (Figure 5). Since Polyak possessed the technical and design expertise to complete the project independently, support for this residency was lighter than previous residencies, consisting of one project team that provided technical support and the coordination of events and promotion of the residency. Polyak's visualization was built using the visual programming language TouchDesigner and required a unique software and hardware configuration. Due to this complex setup and the lack of detailed documentation, the adaptability of this visualization is limited to the James B. Hunt Jr. Library. 


\section{Tally Tracker Explorer}

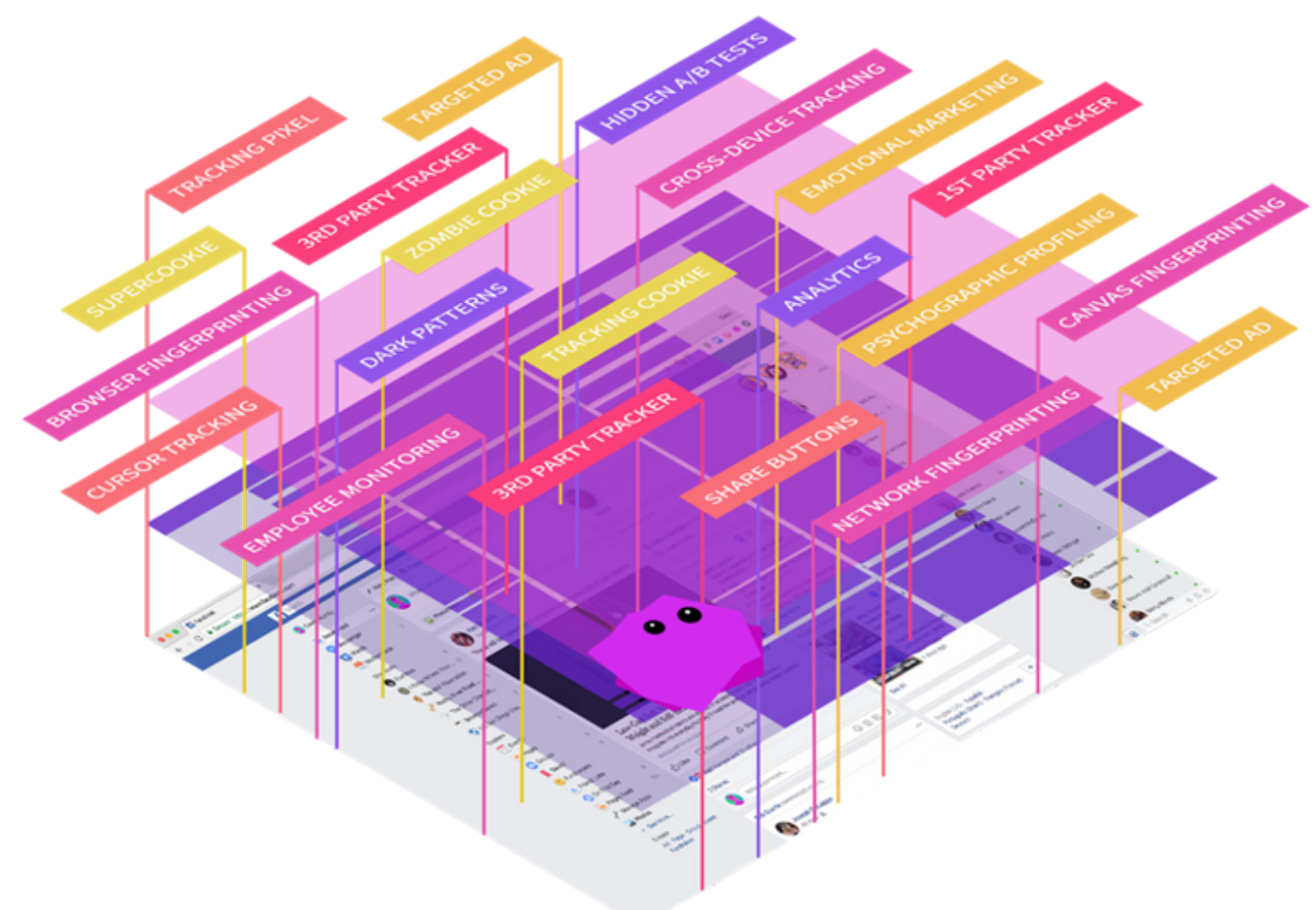

Figure 6: Joelle Dietrick and Owen Mundy's Tally Tracker Explorer, displayed at the NC State University Libraries, Raleigh, North Carolina, in 2020. Image from Sneakaway Studio.

The final Immersive Scholar residency welcomed another duo, Sneakaway Studio's Joelle Dietrick and Owen Mundy. Conducted entirely online in the autumn of 2020 due to COVID-19 safety measures, this residency concluded in a virtual reality experience titled Tally Tracker Explorer, which uncovers data about tracking and surveillance online (Figure 6). Being that this was the last residency, but also the most significantly different in terms of content and logistics, many of the models and lessons learned previously had to be rethought. The management of the project was hands-off and as needed, but the project team was able to provide regular connection through two librarians' technical and data expertise and hire an additional student worker to assist with VR development. Overall, the project development process was similar to previous residencies, but with the addition of a more comprehensive memorandum of understanding and regular and active stakeholder communication circles to maintain the project's momentum and investment. 


\section{Project Team: Changing Roles, Labour, and Crediting Contributors}

As with any large scale, long term project, a significant challenge throughout was the breadth and evolution of roles within the grant management team, which overlapped with specific project support teams. For example, by the end of Immersive Scholar, no one who was originally part of the grant's development was connected to management of it or project work. This was mostly due to turnover for new opportunities and shifting organizational priorities, and it allowed space for the project to flex to include new team members interests, expertise, and ideas. While the ideal is always to have the same group intact through the whole process, the team learned quickly that clearly defined roles and well-developed project and process documentation could substitute for institutional memory in particular employees.

As previously discussed, the team adapted a relatively standard team model for supporting the creative residencies: two support teams focused on specific areas with overlap meetings. Additionally, at the grant management level, the lead and co-PIs held bi-weekly check-in meetings with the project manager in order to maintain momentum and connection between the distributed cohort projects at partner institutions, the creative residencies at NC State, and the goals and objectives of the overall grant. In hindsight, the team recognized that many hands and many fingers in many pies made work that was light, but incredibly diffuse. The expectations of the team had to shift constantly based on the needs of the most immediate subproject, and constantly involving new colleagues in the residency projects, colleagues who were not necessarily aware of the intricacies of the larger grant and its intentions, was a project management challenge in itself. All these realizations underscored the need for process documentation prior to, throughout, and at the conclusion of the various projects. Over the three-year period, the team simplified and honed their documentation practices to account for that need. $\underline{2}$

From the outset, the team was inspired by the dual conversations in open science and digital humanities about evolving models of authorship and contributorship. $\underline{3}$ Knowing that there would be multiple layers of project development, one intentional documentary asset developed was a pilot process to capture and make visible the labour of this work through a contributorship data model. The model uses two taxonomies: the Contributor Roles Taxonomy_(CRediT) and the Taxonomy of Digital Research Activities in the Humanities (TaDiRAH), both of which have strengths and weaknesses for our purpose. The goal in developing and using the contributor data model was less about providing a comprehensive solution and more about testing the 
hypothesis that scholarly works should reveal the many contributions involved (Graban et al.). While the data model is not fully implemented even across the Libraries' projects, the process of thinking about it, struggling to make it work equitably for all partners, and the background research done in preparation for it are all incredibly valuable for conceptualizing how the team should develop projects in the future.

\section{Sustainability, Scalability, and Project Management at Many Levels}

As the project progressed, the already complex grant expanded to incorporate cuttingedge themes, subprojects, and new paths of scholarly exploration. As new residencies formed, theoretical questions arose, and workload increased, challenges emerged around the sustainability, scalability, and management of the grant and its subprojects. Some of the processes to respond to these challenges were resourced and adapted from the Digital Library Federation's Project Managers Toolkit, although for the first two years, none of the team members were trained in project management. In the final year of the grant, the team hired Mildred Nicaragua, a Project Management Professional (PMP) certified project manager, who significantly streamlined the processes.

The importance of considering sustainability within all aspects of the grant, from management to content display, was underscored by rapid growth. Staff turnover early in the grant necessitated thinking about the long-term sustainability of managing a grant with multiple components running simultaneously. Over time, the project management approach shifted to lessen the time burden on most contributing staff by ensuring the core project lead and project manager had significant, dedicated time to manage the grant. This shift helped guarantee longer-term oversight as well as flexibility, which proved crucial to successfully pivoting the project tasks and outcomes during the COVID-19 pandemic. Sustainability of the content, however, remained a constant challenge, as the nature of the grant resulted in multiple subproject creators and owners, including digital artists and multiple universities. With so many different projects and content types, questions arose early about the maintenance and ownership of each product over time.

However, those questions could not be answered without considering the means of displaying the projects, which ties in to the inherent purpose of the grant: to investigate the impactful uses of immersive technology. When projects are designed for custom or cutting-edge technology, they create unique experiences that are difficult, or even impossible, to recreate. Therefore, the team had to consider how to recreate, or, at the very least, capture each experience. Additionally, a persistent challenge was the 
sustainability of the technology itself, as the content was created on and for technology with a limited shelf life: at some point, the technology used currently will be replaced with newer systems, resulting in a known future problem of incompatibility with the software or files. While there is no perfect solution to technology decay, the grant team was certainly not alone in facing this issue and looked to the world of digital humanities and media art for potential solutions. $\underline{4}$

Corresponding with the challenge of sustainability was the challenge of scale, in terms of content distribution and resource allocation. Content sharing was at the heart of the project, and in order to move from displaying content in one location to multiple locations, understanding what sharing requires was crucial. To establish basic requirements, the team asked: What components are necessary? Will other institutions have access to the same software? What expertise is needed to install a piece? To address these questions, the team worked collaboratively and iteratively to identify and integrate the necessary guidelines for inter-institutional sharing. However, scalability remained an ongoing challenge, as each subproject introduced unique requirements. An additional challenge arose concerning resource allocation and the staff time and monetary resources required to sustainably scale up such a large project. The challenge of scaling resources remained persistent, as resource allocation occurred in stages throughout the process. The first resourcing issues arose when determining how many staff to allocate in order to scale the residency model up from singular residencies to multiple back-to-back ones. That same model was scaled up again as the successful residencies drew interest from local NC State faculty, leading to unplanned additional residencies. Logistically, the staff and funding needed to successfully complete a residency did not always match what was available. For instance, one of the creative residency functional teams comprised thirteen people. If the residencies were to grow in number, it would not be possible to dedicate enough staff to provide in-depth support. To combat this challenge, the team employed very thoughtful project scoping and intentional growth to ensure longer-term continuation of the residencies.

Concurrent with the increase in the number of residencies, the project team underwent natural expansion when beginning to address broader questions of immersive scholarship. To pursue this new theoretical direction, the team needed to reassess the required skill sets and work scope. When scaling the project team, the issue became finding internal staff who had the necessary time and expertise or securing funding to consult with an external expert. In the end, redistributing grant funding provided a solution, ensuring that the necessary expertise was available and 
that the project team had stable workloads, and enabled hiring Nicaragua for the final year of the project.

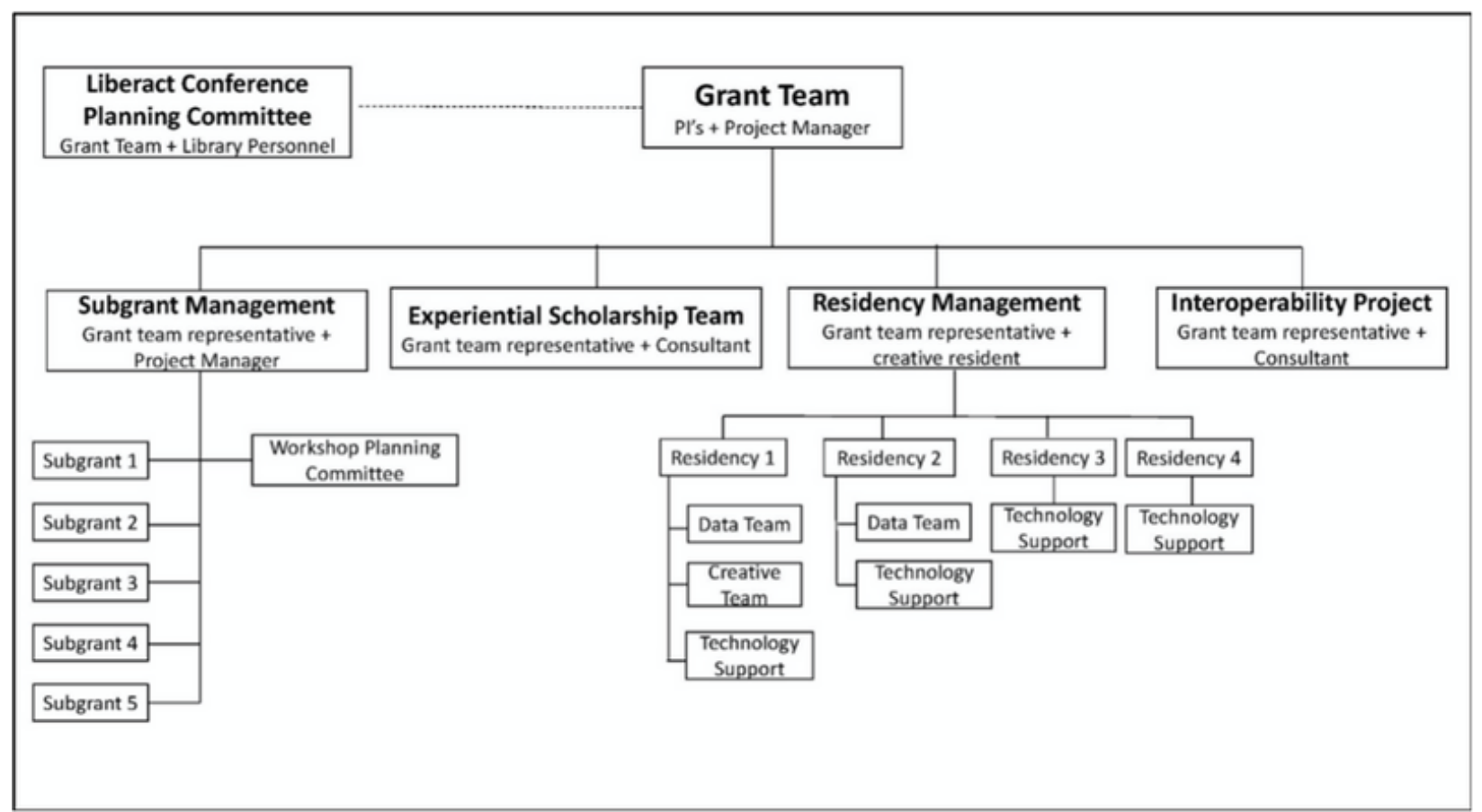

Figure 7: The organizational chart of Immersive Scholar. Diagram by Shelby Hallman.

The final project management challenge stemmed from the hierarchical structure of the grant project, as demonstrated in the organizational chart (Figure 7). Between the grant and each subproject, multiple deadlines, teams, contractors, and priorities needed to be balanced. At the highest level, the priorities were meeting funder deadlines, coordinating funds, achieving grant outcomes, and coordinating with subgrant team leads. At the subproject level, the main priorities were meeting project deliverables, incorporating teams and contractors, aligning outreach and events with university calendars, and delivering expected products. The priorities at the top and subproject levels sometimes corresponded and sometimes differed, resulting in competing priorities for management. For instance, in addition to coordinating cohort participation and meeting milestones, the NC State team needed to manage an initial goal setting workshop, multiple residencies, the Liberact conference--the grant project's culminating symposium, and the creation of guidelines and publications. Overall, each of these tasks required project scoping, team management, time management, and event planning. To lessen the complexity of managing and to distinguish grant and project objectives, each subproject was treated as a unique project rather than just a component of the larger grant. At times the grant project 
manager also served as the subproject manager, while at other times, various team members were tasked with management based on their specific project involvement. Even when the grant manager was the subproject manager, managing each subproject individually helped streamline workflows, differentiate goals and skill sets, and ensure each level of the project was accomplished. Additionally, bifurcating projects and management protected people's time by only involving them in work directly related to their specific subproject while clearly distinguishing management priorities. In the end, even with the project-based approach, management was complex and fluid.

\section{Guidelines, Workflows, and Documentation Model}

In order to manage the grant, address its multilayered complexity, complete its subprojects, and meet its goals, the principal investigators shifted to the aforementioned project development process, focusing on guidelines and workflows to support the various activities relevant to the broader community of immersive visualization. $\underline{5}$ These resources cover the spectrum of phases for immersive visualization practice, from initial space and services planning to the production, dissemination, and evaluation of immersive visualization content. They include the visualization space planning framework developed at VCU, the establishment of shared expectations with creative residents, and guidelines for documenting, testing, and evaluating immersive visualization applications developed at NC State.

Beginning with the initial phase of immersive visualization practice, VCU's contribution, $\underline{\text { A Common Framework for Planning Visualization }}$

Environments (Johnson), serves as a consultation resource for institutions planning to develop new immersive visualization spaces and services. Based on research of existing visualization environments and input from various practitioners involved in immersive visualization, this document details the necessary considerations and actions of a planning team at various stages of the process. It incorporates direct quotes from practitioners in the field, outlining best practices based on first-hand experience and helpful checklists to incorporate into the planning process. Moving forward, this work could be considered as the de facto guide for institutions considering whether and how to invest in new visualization spaces.

In support of the content development phase of immersive visualization practice, the NC State University Libraries developed guidelines for creative residency programs to establish shared expectations between the scholar/artist and the institution, including when and how to establish them. For each resident, expectations were communicated early, prior to their acceptance of the residency and again at the 
start of the residency. This set an initial understanding of the requirements and scope of the project, such as expectations about open source licensing and community engagement, as well as the financial and logistical aspects of the residency, for example, the payment schedule and the provision of staff time and facilities resources.

Regarding the phase of dissemination and evaluation of immersive content, as new software applications and frameworks were produced over the course of the grant, the need arose to validate their usability and whether they could be disseminated across disparate immersive environments. The grant team approached this challenge from the perspective of both the creators and the evaluators, in this context evaluators are defined as the individuals responsible for approving the display of content in an immersive environment. The team also reviewed the technical dependencies and aesthetic qualities of new works; the guidelines for the technical review are collected in Documentation and Testing Guidelines for Immersive Digital Applications (Gurley).

For the content creator, a template was created providing recommendations for the minimum information that should be included in the documentation delivered with an immersive visualization application. This template follows basic standards for software documentation while also including additional considerations for applications meant to be shared and used in immersive display environments. These additional considerations include display specifications such as the display type (e.g., is this application usable on a large scale display, VR headset, etc.), display size (e.g., considerations for the pixel size, physical size, or aspect ratio of a display), and interactive devices required for an application to function as intended by the creator. They also include detailed installation instructions that are useful for individuals with various degrees of technical skill and supporting images and descriptive text that demonstrate the appropriate appearance and function of an application in situ. This documentation is intended to define and demonstrate the scalability of a given application and support the deployment process for content managers with varying amounts of technical experience.

The grant team developed a set of guidelines for conducting a systematic evaluation of an application to support content managers in validating interoperability. These guidelines include a series of questions about the evaluator and the device on which an application is tested, the technical performance of an application on the specified device, and the possible usefulness of the application given the expected audiences. Given the diversity of technical experience content managers may have across institutions, the first set of questions identifies the role of the evaluator in supporting 
the immersive technology as well device specifications such as screen size, operating system, and hardware specifications. The second set of questions evaluates how an application performs in the environment defined in the first section. These questions first determine the technical aspects of performance, documenting the evaluator's experience installing, launching, and interacting with the application and identifying any noticeable issues in appearance or performance. They then determine the usability of the content for the expected end users of the application in the immersive environment. In practice, this evaluation report would be provided to the content creator to either support the interoperability of an application and help to define the degree of scalability of an application or to prompt updates or modifications to the application to support broader scalability.

The guidelines and workflows described here supplemented the project development process and will provide supporting documentation for future use cases in immersive visualization practice. Every effort was made to make these resources publicly accessible through the Immersive Scholar documentation hub on Open Science Framework. A Common Framework for Planning Visualization Environments is available as a PDF document, while the Documentation and Testing Guidelines for Immersive Digital Applications are provided in Markdown format, a common format for documentation files such as README, for easy incorporation into existing software documentation. They include links to example forms to be provided with the testing guidelines to promote systematic data collection. A final output from Immersive Scholar that extends, theorizes, and offers case studies from these guidelines and workflows is Immersive Scholar: A Guidebook for Documenting and Publishing Experiential Scholarship Works (Mann and Vandegrift), released in March 2021 through a partnership with the UNC Press Office of Scholarly Publishing Services.

\section{Conclusion}

The Immersive Scholar grant project included the development of new software, content, workflows, and ancillary documentation, achieved by a small grant management team, disparate local teams for the creative residency projects, and a cohort of affiliated organizations with their own management teams, structures, and processes. This article illustrates that adaptability in process is a virtue, and that multiple manners and forms of documentation can create a project throughline, allowing multiple stakeholders and partners to contribute to a project with clarity. Furthermore, the team notes that a conceptual framework of "project development" tended to be more helpful at times than more traditionally defined project 
management. Thinking of Immersive Scholar as a project development process allowed the team to consider a wide range of topics, such as contributorship, and to operate the cohort, the creative residencies, and the shifting roles and members in the grant management team under a "lazy consensus" paradigm, with a bias toward action (Nowviskie, "Lazy"). Immersive Scholar contributes to the continuing evolution of new forms of scholarship, examining how we validate and credential, circulate and maintain them. We hope that sharing what learned through this grant project will help propel us toward a more open, equitable, and engaged future for the academy.

\section{Works Cited}

Borek, Luise, Quinn Dombrowski, Jody Perkins, and Christof Schöch. "TaDiRAH: A Case Study in Pragmatic Classification.” Digital Humanities Quarterly, vol. 010, no. 1, Feb. 2016, www.digitalhumanities.org/dhq/vol/10/1/000235/000235.html.

“The Conserving Computer-Based Art Initiative." Guggenheim, 2021, www.guggenheim.org/conservation/the-conserving-computer-based-art-initiative.

Dietrick, Joelle, and Owen Mundy. Tally Tracker Explorer. NC State University Libraries, Raleigh, North Carolina, 2020. doi.org/10.17605/OSF.IO/YVE95

Dombrowski, Quinn. “TaDiRAH: Building Capacity for Integrated Access.” Dh+lib, 21 May 2014, acrl.ala.org/dh/2014/05/21/tadirah-building-capacity-integrated-access/.

Edmond, Jennifer, and Francesca Morselli. "Sustainability of Digital Humanities Projects as a Publication and Documentation Challenge." Journal of Documentation, vol. 76, no. 5, Emerald Publishing Limited, Jan. 2020, pp. 1019-31. Emerald Insight, doi.org/10.1108/JD-12-2019-0232.

Visualizing Objects, Places, and Spaces: A Digital Project

Handbook. https://handbook.pubpub.org/. Accessed 17 June 2020.

Foley, Caitlin, and Misha Rabinovich. Surface Tension. NC State University Libraries, Raleigh, North Carolina, 2019, NC State University Libraries, Raleigh, North Carolina. doi.org/10.17605/OSF.IO/W4RK6 
Fostano, Katherina and Laura K. Morreale. "The Digital Documentation Process." The Digital Documentation Process, 31 Jan. 2019, digitalhumanitiesddp.com/. Accessed 17 June 2020.

Graban, Tarez Samra, Paul Marty, Allen Romano, and Micah Vandegrift. "Introduction: Questioning Collaboration, Labor, and Visibility in Digital Humanities Research." Digital Humanities Quarterly, vol. 13, no. 2, 2019, www.digitalhumanities.org/dhq/vol/13/2/000416/000416.html.

Greenberg, Jonathan, David Millman, Jeremy Morse, Thib Guicherd-Callin, and Karen Hanson. "Preservation of New Forms of Scholarship." YouTube, uploaded by CNI: Coalition for Networked Information, 22 May 2020, www.youtube.com/watch? $\underline{\mathrm{V}=081 \mathrm{aiEMm} \mathrm{I0}}$.

Gunn, Chelsea, and Aisling Quigley. "Project Management as a Path for Sustaining Digital Humanities Scholarship." Project Management in the Humanities, Digital Humanities Summer Institute, 6 June 2020, University of Victoria, Victoria, BC. Conference Presentation.

Gurley, Walt. Documentation and Testing Guidelines for Immersive Digital Applications. OSF, osf.io/7hmcyl.

Gurley, Walt, Erica Hayes, Micah Vandegrift, and Markus Wust. "Three-Fold Approach." Immersive Scholar, 10 Dec. 2018, www.immersivescholar.org/news/threefold-approach.

Hansen, David, Liz Milewicz, Paolo Mangiafico, Will Shaw, Mattia Begali, and Veronica McGurrin. Introduction. A Framework for Library Support of Expansive Digital Publishing, by Hansen et al., Duke University Libraries, 2019, doi.org/10.21428/680f3353.

Haskett, Mary E., and Suman Majumbder. Food and Housing Security Among NC State Students. NC State University, Feb. 2018, dasa.ncsu.edu/wpcontent/uploads/sites/131/2020/06/NC-State-Food-and-Housing-Insecurity-1.pdf. Haskett, Mary E., Dana Kotter-Grühn, and Suman Majumder. "Prevalence and Correlates of Food Insecurity and Homelessness Among University Students." Journal of College Student Development, vol. 61 no. 1, Jan.-Feb. 2020, pp. 109-14. Project MUSE, doi.org/10.1353/csd.2020.0007. 
The Information Maintainers. Amelia Acker, Hillel Arnold, Juliana Castro, Scarlet Galvan, Patricia Hswe, Jessica Meyerson, Bethany Nowviskie, Monique Lassere, Devon Olson, Mark A. Parsons, Andrew Russell, Lee Vinsel, and Dawn J. Wright. Information Maintenance as a Practice of Care: An Invitation to Reflect and Share.

2019. Zenodo, doi.org/10.5281/zenodo.3251131.

Johnson, Eric. A Common Framework for Planning Visualization Environments. 2020. OSF, osf.io/wft2h/.

Klein, Martin, Harihar Shankar, Lyudmila Balakireva, and Herbert Van de Sompel. “The Memento Tracer Framework: Balancing Quality and Scalability for Web Archiving." Digital Libraries for Open Knowledge, edited by Antoine Doucet et al., Springer International Publishing, 2019, pp. 163-76. Springer

Link, doi.org/10.1007/978-3-030-30760-8 15.

Koeser, Rebecca Sutton. “Document ALL the Things!” Center for Digital Humanities @ Princeton University, 12 Aug. 2019, cdh.princeton.edu/updates/2019/08/12/documentall-things/.

LaFleur, Liss. Coded Glass. NC State University Libraries, Raleigh, North Carolina, 2018. doi.org/10.17605/OSF.IO/QZBEW

Larivière, Vincent, Nadine Desrochers, Benoît Macaluso, Phlippe Mongeon, Adèle PaulHus, and Cassidy R. Sugimoto. "Contributorship and Division of Labor in Knowledge Production" Social Studies of Science, vol. 46, no. 3, pp. 417-35, 21 June 2016. SAGE Journals, https://doi.org/10.1177/0306312716650046.

Lozano-Hemmer, Rafael. Best Practices for Conservation of Media Art from an Artist's Perspective. Antimodular Research, 28 Sept. 2015, github.com/antimodular/Bestpractices-for-conservation-of-media-art.

Mann, Abigail E., and Micah Vandegrift. Immersive Scholar: A Guidebook for Documenting and Publishing Experiential Scholarship Works. University of North Carolina Press, 2021. doi.org/10.5149/9781469664286_Mann.

Nowviskie, Bethany. "Evaluating Collaborative Digital Scholarship (or, Where Credit Is Due)." Journal of Digital Humanities, vol. 1, no. 4, Fall 2012, journalofdigitalhumanities.org/1-4/evaluating-collaborative-digital-scholarship-by= bethany-nowviskie/. 
Nowviskie, Bethany. "Lazy Consensus.” Bethany Nowviskie, 10 Mar.

2012, nowviskie.org/2012/lazy-consensus/.

Polyak, Emil. Untitled. NC State University Libraries, Raleigh, North Carolina, 2019.

Sazdanović, Radmila. Tess-Celestial. 2018. NC State University Libraries, Raleigh, North Carolina, 2018. doi.org/10.17605/OSF.IO/DYJ6T

Shepherd, Ammon, Amanda Wyatt Visconti, and Lauren Work. "Archiving DH Part 4: Solutions." Scholars' Lab, 28 June 2019, scholarslab.lib.virginia.edu/blog/archiving-dhpart-4-solutions/. Accessed on November 24, 2020.

Swick, Lucas. Community Gardens. NC State University Libraries, Raleigh, North Carolina, 2018, NC State University Libraries, Raleigh, North Carolina. doi.org/10.17605/OSF.IO/CGX5Q.

“A Symposium on Preserving Contemporary Cultural Heritage.” University of Pennsylvania Libraries, 2019, www.library.upenn.edu/about/exhibits-events/symposiumpreserving-contemporary-cultural-heritage.

Vandegrift, Micah, Shelby Hallman, Walt Gurley, Mildred Nicaragua, Abigail Mann, Mike Nutt, Markus Wust, Greg Raschke, Erica Hayes, Abigail Feldman, Cynthia Rosenfeld, Jasmine Lang, Kelsey Dufresne, David Reagan, Eric Johnson, Chris Hoffman, Alexandra Perkins, Patrick Rashleigh, Robert Wallace, William Mischo, Elisandro Cabada. Immersive Scholar. OSF, doi.org/10.17605/OSF.IO/3Z7K5

Vasilevsky, Nicole A., Mohammad Hosseini, Samantha Teplitzky, Violeta Ilik, Ehsan Mohammadi, Juliane Schneider, Barbara Kern, Julien Colomb, Scott C. Edmunds, Karen Gutzman, Daniel S. Himmelstein, Marijane White, Britton Smith, Lisa O’Keefe, Melissa Haendel, and Kristi L. Holmes. "Is Authorship Sufficient for Today's Collaborative Research? A Call for Contributor Roles." Accountability in Research, vol. 28, no. 1, 2021, ), doi.org/10.1080/08989621.2020.1779591.

\section{Footnotes}

1. The Immersive Scholar team intentionally strove for what The Information Maintainers refer to as a Practice of Care in approaching this challenge. The project, then, was not just to build new technologies to make visualization easier across spaces, but also to adopt a care-ful, sustainable method for addressing the challenge (The Information Maintainers). $\subseteq$ 
2. Much of the inspiration for our documentation practices came from Chelsea Gunn and Aisling Quigley's SocioTechnical Sustainability Roadmap, presented at DHSI 2020 as "Project Management as a Path for Sustaining Digital Humanities Scholarship," and Katherina Fostano and Laura Morreale’s Digital Documentation Process. $\doteq$

3. With too many sources, informal conversations, and inspiring blog posts to list, we are indebted to the work of Cassidy Sugimoto, Daniel Katz, Bethany Nowviskie ("Evaluating"), Quinn Dombrowski, and their many co-authors and collaborators for the broadening recognition of the labour of research and scholarship. See Graban et al. for deeper insight into the specific ideas captured from these and other sources. $\bullet$

4. We are particularly indebted to the work of Ammon Shepherd et al., Jennifer Edmond and Francesca Morselli, Rebecca Sutton Koeser, Martin Klein et al., Rafael Lozano-Hemmer, Jonathan Greenberg et al., as well as the Symposium on Preserving Contemporary Cultural Heritage and the Conserving Computer-Based Art Initiative. $\bullet$

5. As examples of process documentation, we were following the lead of our colleagues at Duke University and their multiple efforts in this area, outlining new processes by which libraries support new forms of scholarly work: see "Visualizing Objects" and David Hansen et al. $\_$ 